\title{
Teaching and Learning through Wikis in Higher Education
}

\author{
Rui Gomes and Lígia Sousa
}

\begin{abstract}
Higher education institutions (HEIs) can, like any other organisation, profit from the advantages of using web 2.0 tools, as these institutions need to balance acquisition processes with learners' participation and contributions. The use of these tools in training processes can contribute to pedagogical innovation and to developing students' learning and professional skills; thus, it must be promoted. This paper presents a case study which aims to validate the desired Wiki outcomes in a teaching and learning experience in the Information System Management classes of a Management Course in a Portuguese HEI, as well the importance of the Wiki for the regional community of management professionals. The results of the analysis of the information gathered during this pedagogical experience suggest that group process skills and behaviours regarding self-organization, integrity and openness clearly develop more (or are at least more easily perceived) than web skills, as do some editing skills.
\end{abstract}

Index Terms-Wikis, pedagogical approach, group processes skills and behaviours of self-organization, integrity and openness.

\section{INTRODUCTION}

Pedagogical innovation addresses the potential of information and communication technologies (ICT) in general, and social computing in particular, to transform learning and teaching processes, offering novel ways of learning by supporting, among other things, learner-centered learning approaches, group work and inquiry projects, interactive forms of learning that lead to more reflective, deeper and participative learning, learning-by-doing, inquiry learning, problem solving and creativity [1]. Many constructivist theorists posit that learning is a social process and occurs through interactions and sharing information with each other. Additionally, researchers argue that collaborative learning helps students to retain information better than by doing individual work. In addition to social learning, many theorists cite active participation as a major component of effective learning environments [2].

According to constructivist theory, meaning is gained through active learning, social interaction, and the construction of knowledge [3]. Constructivist theory also suggests that meaningful learning is dependent on a rich and relevant context. Contextual Teaching and Learning, an instructional systems theory that schools and higher educational reform movements are steadily adopting, is "based on the premise that meaning emerges from the relationship between content and its context".

Manuscript received April 9, 2013; revised July 10, 2013.

The authors are with the Instituto Politécnico de Viana do Castelo, Escola Superior de Tecnologia e Gestão, Av. do Atlântico, 4900-348, Viana do Castelo, Portugal (e-mail: rgomes@estg.ipvc.pt, ligia@estg.ipvc.pt).
Social computing facilitates pedagogical innovation by disrupting traditional learning and teaching patterns, giving rise to new and innovative ways of acquiring and managing knowledge. Social computing tools (blogs, Wikis, social networks, and social bookmarks, etc.) are expected to enhance learning processes and outcomes in a number of ways. Firstly, it is believed they will respond better to the changed cognitive processes and learning patterns that have evolved due to the ubiquity and widespread use of ICT's, thus facilitating knowledge acquisition. Furthermore, they reflect currently communication and working patterns and are thus better fitted to preparing learners for the demands of society and endowing them with the necessary skills for a successful professional career [4]. Moreover, social computing tools recognise the diversity of users and, therefore, are expected to contribute to the personalisation of educational experiences, offering opportunities for flexible, distributed learning, which could provide learners with more varied opportunities to engage with learning and develop their own creative skills [5]-[8]. Thus, social computing applications are expected to promote independent, autonomous and self-directed learners endowed with a variety of social skills that enable them to connect, interact and collaborate successfully with a variety of people on different tasks and in diverse environments.

Learning 2.0 is an emergent phenomenon fostered by bottom-up take-ups of social computing (or 'Web 2.0') in educational contexts. Learning 2.0 approaches make use of different sensory channels for learning and can provide more engaging learning environments; they support the implementation of collaborative projects, which enable learners to tap the tacit knowledge of their peers and develop their own ideas in a creative and supportive environment; and they allow learners to connect with societal players outside the boundaries of formal education, enriching learning experiences and better preparing learners for life in a globalised world.

While many traditional web applications focus on the delivery of content, Web 2.0 applications, such as blogs, Wikis, social networks, and social bookmarks, focus more on social connectivity. These Web 2.0 applications are driven by users' contributions and interactions, unlike most of the sites of the Web 1.0 era. In this way, Web 2.0 applications provide venues for collaboration and the sharing of information, supporting the networks for social and active learning. Using Web 2.0 technologies such as Wikis to supplement in-class instructions could create an interactive, collaborative, learning experience for students, in a media context with which they are familiar.

A Wiki is a tool which can be used in multiple ways. Wikis (What I Know Is) refer to collaborative websites that allow users to interact by adding, removing, or editing site content. 
A Wiki project can provide the tools and collaborative work space that enable contextual teaching and learning. As such, according to contextual teaching and learning principles, the role of the instructor is not to provide learning. The role of the instructor is to provide the context in which learning can occur. Contextual teaching and learning engages students in significant and relevant activities that help them connect their academic learning to real-life situations and problems.

Johnson [9] suggests that when students are provided with a rich context and the tools for learning, they achieve higher levels of learning, see a stronger relevance between the problems in the classroom and the problems of the real world, and are more satisfied with the learning experience. When students formulate projects or identify interesting problems, when they make choices and accept responsibility, when they search out information and reach conclusions, when they actively choose, order, organize, touch, plan, investigate, question, and make decisions to reach objectives, they connect academic content to the context of life's situations, and in this way they discover meaning.

Wikis enable teachers to become authors and editors of content, plans, goals, ideas, and resources within a community. Attempts at school improvement cannot be individual and fragmented; rather, they must be embedded in collaborative practices that address the day-to-day needs of students. The future may see Wikis as the primary vehicle of professional collaboration, because Wikis can be used in a variety of ways. Teachers who see value in collaboration will use Wikis as a strategy to communicate, share, and find consensus in their methods, ultimately making the difficult job of teaching a little less stressful. Wikis are a communicative medium that assists teachers in an important aspect of their job. Wikis are indeed a powerful and useful tool.

Student collaboration encourages higher-level thinking strategies and online collaboration which utilizes Web 2.0 technology, one that most students have already embraced, provides a comfort zone for that collaboration to take place. Wikis enhance asynchronous communication and cooperative learning among students, and they promote cooperation rather than competition [10].

By incorporating Wikis into the school workplace, educators can better prepare students to make innovative uses of collaborative software tools and collaborate with their peers. These are the skills valued by the business community as key innovations in the business practices of today, and in the future.

\section{A. Skills for Learning in a Knowledge Society}

Current learners live in a world that is characterised by information overload [11]. By its nature, the web rewards comparison of multiple sources of information, individually incomplete and collectively inconsistent. This induces learning based on seeking, sieving and synthesising, rather than on assimilating a single "validated" source of knowledge such as from books, television, or a professor's lectures [11], [12]. Apart from the skills needed to manage the abundance of information available, learners need additional skills to react to the challenges of a digital society and to counterbalance the deficiencies of their natural learning styles. Three common learning objectives emerge as being relevant for learning in a knowledge-based society:

1) Reflective, critical and evaluation skills: Individuals must be empowered with the necessary skills to recognise, evaluate and seize opportunities for self-realisation and learning. They need to be able to critically reflect on the content and process of learning, to recognise their own skills, weaknesses and strengths, identify side-effects and limitations of their actions, and respect the legal, social and ethical constraints on their personal endeavours.

2) Collaboration and communication skills: Individuals need to be able to communicate effectively in a variety of situations, tolerating diversity and constructively dealing with conflict. They need to be able to collaborate with others in heterogeneous groups, bringing in their competences and seeking support and assistance for their personal goals in an adequate and constructive way.

3) Pro-active attitude, innovation and creativity: Individuals must be enabled to take responsibility for their own learning process throughout life, actively seizing opportunities for self-realisation. Motivation and confidence in one's own ideas and capabilities are important pre-requisites for innovation and creativity. Individuals will, therefore, have to be empowered to creatively and critically develop their ideas in interaction with others, assuming responsibility for, and ownership of, their actions and products.

\section{B. Fundamental Skills - Keys to Wiki Success}

Although the existing literature on learning in the digital commons and on the nature of online collaborative writing is relatively slim, case studies and qualitative reports have suggested several characteristics as keys to Wiki success [13]-[17]. Successful collaborative online writing is dependent not only on cognitive skills, such as Web skills and writing, but also on a number of affective, or values-based behaviors.

Cognitive Skills - Also called prerequisite skills, these are the basic fundamental skills that students will need in any Wiki project.

Writing and Constructive Editing Skills - Every Wiki project is, at its core, a collaborative writing project dependent on skills in research, writing, and editing. It further facilitates the process by helping students understand constructive editing: both how to edit and when to edit.

Web Skills - Every Wiki project is fully constructed on the Web. Students will, therefore, need to be reasonably comfortable with accessing the Internet, using Web browsers, tracking logins and passwords, writing with embedded Wiki HTML editors, and working with digital images or other Web media. Experienced online students will be well versed in at least some of these Web skills. Nevertheless, at the start of a project it is useful to gain a clear understanding of each student's confidence and skill with Web-based technologies.

Group Process Skills - These skills tend to vary the most from student to student and group to group. According to Johnson and Johnson [9], to be effective, group members must be able to set goals; communicate clearly; share leadership, participation, power, and influence; make effective decisions; engage in constructive controversy; and negotiate conflict. 
Personal Characteristics in addition to cognitive skills, each group member will bring a set of values and personal characteristics to the project. As discussed earlier, millennial students and working adults have developed these characteristics through prior development, learning, and work experiences.

The following are characteristics that stand out in the literature as keys to successful online collaboration:

- Openness - Openness is probably the most challenging characteristic required in a Wiki project. As suggested by Tapscott and Williams [14], working in a Wiki opens up each contributor's ideas to scrutiny and criticism. Students in a Wiki project must be open, not only to suggestions but also to others modifying, reorganizing, and improving their contributions [16].

- Integrity - The group's ability to build trust is largely dependent on the integrity (or trustworthiness) of each of its members. Integrity can be perceived in several ways: through the accountability of each student (for example, the student does what he says he is going to do), through the honesty of each student (for example, the student says what he means), and through the competence of each student's contributions (for example, the student's contributions are accurate and demonstrate knowledge or expertise). Because a Wiki project is completed online and often without the benefit of real-time dialogue, this integrity must come through in the student's written communication and Wiki contributions.

- Self - Organization - Self - Organization is the ability to see and adjust one's own behaviour in relation to one's environment. Students who engage in self-organization, "assume responsibility for their own decisions and conduct, appraise alternatives, make choices, develop plans, analyse information, create solutions, and critically evaluate evidence". Self - organization requires metacognition, self-assessment, and the ability to adjust to environmental feedback.

\section{THE CASE}

In order to validate the improvement in skills, both those that are essential for the use of Wikis and those that, according to the literature, are likely to be developed through Wiki activities with students at HEIs, a class of Information Systems Management (ISM), in the 2nd year of the Management Course (MC) at the School of Technology and Management of the Viana do Castelo Polytechnic Institute (ESTG/IPVC) as a case study. The use of such skills in these students was explored, through the introduction of an activity involving creating a Wiki in the teaching-learning process, during the semester.

\section{A. Research Method}

Olesen and Myers's research [17], which investigates the relationship between the introduction of groupware into an organization and the consequent changes in individuals' work habits and the structure of the organization, was supported by action-research method. The authors argue that the method "enables a researcher to intervene in the organization while at the same time generate knowledge about the process.". They approached research in an interpretive manner, which allowed them to focus their research on how individuals attempted to make sense of the specific situation. Like these authors (ibid), we employed a five-stage action research cycle. The stages are as follows:

- Diagnosing: identifying the research question

- Action Planning: determining the actions to be undertaken to address the research question

- Action Taking: conducting and monitoring the planned actions

- Evaluating: determining if the actions have addressed the research question

- Specifying Learning: documenting the knowledge obtained by conducting the project.

\section{B. Diagnosing}

As the use of Web 2.0 tools can play an important role in developing students' professional skills in higher education contexts, we need to use these tools to perform pedagogical innovation; Taking into consideration the advantages regarding the use of Wikis in the teaching and learning context and the type of outcomes obtained [18], our main aim is to validate the enhancement of Learning Outcomes (Direct), Metacognitive Outcomes (Indirect), and Collaboration Outcomes (Indirect) of the students who attended the curricular unit of Information Systems Management in a HEI (ESTG/IPVC) in Portugal, through an activity involving the construction of a Wiki developed over the course of one semester with the respective students.

\section{Action Planning}

After reviewing literature on the use of Wikis in teaching and learning contexts, we planned the Information Systems Management classes (ISM), in the 2nd year of the Management course of the ESTG/IPVC, based on a constructivist pedagogy, through which we defined goals, contents, learning strategy and resources. It was then that the activity of creating a Wiki was considered.

The direct desired outcomes for this project were the students' acquisition of the main concepts used in the field of Information Systems (IS), as well as the different types of IS, and to relate these with the various activities of the organization. The contents supported by these objectives were: different types of IS: Enterprise Resource Planning, Customer Relationship Management, Supply Chain Management, Business Intelligence and Web 2.0 Tools.

The desired metacognitive outcomes were future learning skills and behaviours developed by the students. Collaboration outcomes answer the question "What collaborative skills and abilities might students develop as a result of this project?"

The Wiki project followed a basic instructional design process and included the following steps.

The teacher was responsible for the tutoring of the students' research, and for providing some training so that students were able to use these tools in an appropriate way (Wiki), before starting to work with it. This included some information and materials about how to create, manage and create contents (commands) in a Wiki.

The teacher built the structure of the Wiki so that it could be used by the various groups of students. The Wiki frame 
included a home page with an introduction to the purpose and goals of the Wiki project. It also included a menu or table of contents with links to content pages and team profiles, and guidelines for contributors.

A temporary starting support structure was proposed to students regarding building Wiki on Enterprise Information Systems (EIS), supported by bibliography and websites (they needed to prepare contents about definition, functionalities, implementation strategy, suppliers and success cases). The students (attending both day and evening classes) were organized into working groups of two or three students per group from different classes dealing with the same EIS. Each group was allowed to access only one EIS, and only groups with the same subject could insert content and organize the information in the ISM Wiki.

The students were required to participate and they were evaluated according to the introduction of contents and the organization of the Wiki. Students' work was assessed according to the final contents of the ISM Wiki (as a result of the whole semester's work) as well as through a formal written assessment about types of EIS. Assessment of the activity included the results of each student's interventions (from each group), and the quality of the results with regard to the structure and contents of the IS assigned, created in ISM Wiki, with a rating for each student in the various groups involved and for the assessment of these contents.

Bearing in mind that the students involved are in higher education, we went from the principle that it would not be necessary to emphasize their writing skills' development, (even taking into account that the activity also demanded writing skills from the groups working on the Wiki), a process that progresses through phases of brainstorming, outlining, elaboration, editing, and refinement. Nevertheless, considering that there were less evident and less developed skills in these students (such as collaborative skills), we focused our attention on those skills and not on writing). On evaluating the final contents of the Wiki, we did take into account editing skills, given that the final product, the Wiki, also depended on these skills on the part of the students.

The Indirect desired outcomes (Metacognitive outcomes) were future learning skills and behaviours developed by the students; collaboration outcomes answer the question "What collaboration skills and abilities might students develop as a result of this project?" was evaluated by two instruments.

Taking into account the fact that social computing is a means of facilitating access to information by current and prospective students, making institutional processes more transparent and facilitating the distribution of educational material, we also used this Wiki to encourage the involvement of third parties - prospective future employers or external experts - exploring this involvement through an open questionnaire that was applied to SMEs in the region.

\section{Action Taking}

Before the semester-long task of building a Wiki in the curricular unit of ISM, the students who were involved were all evaluated in order to identify their skills with regard to what are considered by West and West [18] to be the necessary skills for building and developing Wikis. This was done with the aim of the identifying whether the participating students had those skills and, if so, to what level, before beginning the task of building the Wiki.

The skills and behaviours which were evaluated:

- Group processes skills and behaviours of self-organization, integrity and openness;

- Web skills

A work session was organised with students divided into small groups who were given tasks aimed at assessing the above-mentioned behaviours and skills. Each student was listed on a record sheet, on which two observers (assessors) noted each instance of a skill or behaviour manifested by any of the members of the groups.

The main task of each group was to develop a brochure to 'advertise' the Management course. The existence or lack of group processes skills and behaviours of self-organization, integrity and openness were observed as the task was carried out. These were noted on a checklist of the behaviours detailed by West and West [18], as referred to above, for each student.

Web skills were evaluated by means of a questionnaire. The results obtained are shown according to skills groups.

\section{1) Group processes skills and behaviours of}

self-organization, integrity and openness

The behaviours and skills which were identified overall included: punctuality and attendance over the period in which the task was carried out; the easy expression of opinions and clear communication of the students' own ideas; the ability to listen to others; time management; respect for the other group members, and articulation between the group's aims and actions.

Less frequent was the introduction of new ideas as the task evolved, as was difficulty on the part of the students to accept suggestions from their companions and to adopt those suggestions in order to carry out the task in hand, modifying process or results. In the same way, there was little awareness of who needed help and few offers of help. Moreover, there was an uneven distribution of the workload across all of the groups.

Finally, it was not possible to observe some of the behaviours on the checklist in the task given (only when the assessors were observing did they realise that the task did not facilitate these types of behaviours and that another type of task would be necessary for this. Therefore, they were eliminated from the process and the remaining items were considered to be adequate indicators of the skills necessary to elaborate Wikis).

The items which could not be observed were the quality of the completed tasks, the ability to research and gather data for the tasks and the ability to differentiate between main points and details.

In sum, it can be concluded that regarding group processes skills and behaviours of self-organization, integrity and openness, the skills that were most lacking in terms of those necessary for developing Wikis were, even before carrying out the respective activity, there was difficulty in terms of the equal distribution of tasks and responsibilities, as well as problems in accepting and following other people's suggestions (skills which can be considered very important for the tasks which the students would have to carry out throughout the semester, as each group would have to be open to, and prepared for, feedback on both an individual and 
group level, as well as from other groups, so that all the Wikis could be modified, developed and improved). Perhaps the fact that all the students found it difficult to help and be aware of those who needed help is linked in part to the difficulty shown in accepting and following suggestions (which is in fact a problem with accepting spontaneous help from others, correcting/altering process and results; consequently, this can be seen as an attitude which brings into question the quality of their own work/task).

\section{2) Web skills}

Most students had already done the following tasks on the internet: used a browser, printed a webpage, downloaded something from the internet, unzipped and/or opened documents and programmes from Internet sites (for example, visual material, HTML, demonstrations of applications, presentation files and PDF files), bookmarked pages for later use without having to type in the complete web address, accessed databases (Acess, SQL, FMPro) and Wikis (Wikipedia, Wikispaces). Many of them said that they had only created content on Facebook. The majority had used the following tools: Office tools (Word, Excel, Powerpoint), databases (Acess, SQL, FMPro), Social Networking sites (MySpace, Facebook, MeetUp), content-sharing sites (Flickr YouTube, Del.cio.us), Wikis (Wikipedia, Wikispaces), and Blogs (Blogger, LiveJournal, JotSpot).

(As previously stressed, there were no significant changes observed in terms of improved web skills in the participating students after the Wiki building task, except of course for the carrying out of content-creating activities, as was first envisaged).

\section{3) Evaluation of skills after carrying out and completing} the activity tasks

At the end of the semester, after the task of building a Wiki had been completed, the skills which had been identified and assessed in the first instance were re-evaluated. These were skills which, on the one hand, were considered fundamental in order to carry out the task in hand and, on the other, were skills that were considered to be the objective of this particular task, to be developed to a higher level. Our aim was to explore how well these skills would be developed through such a task in our students.

In order to identify changes and improvements in group processes skills and behaviours of self-organization, integrity and openness post-task, two instruments were applied in order to gather data. One was a scale with nine items, each referring to one or more of the various skills developed through the building of a Wiki, and each with for different possibilities in terms of points given to the degree of development achieved as an individual or as a group in these skills. The scale was based on research by West and West[18] and adapted to the particular task carried out in this action research.

The other instrument was a questionnaire with five open questions regarding the results and benefits achieved by each group by carrying out the specific task:

- What tasks in the activity were not carried out in your group?

- What were the most important things you learned from doing this activity?
- What gave you the most satisfaction in this activity?

- What advice or suggestions would you give to groups who were going to carry out a similar activity to the one you did?

- What would you like to say to your the members of your group, on these two lines?

In order to evaluate improvements in Web skills, the same questionnaire which had been used initially was applied.

At the end of the semester, the questionnaire was also applied to managers in order to find out whether the information made available in the Wiki was useful and to investigate the possibility of them taking an active part in the elaboration of the Wiki in future.

During the semester, the classes went ahead according to what had been planned, and students were guided by the teacher to search for information in bibliographical sources and the Internet in the classes, in order to introduce and organize content in the ISM Wiki. The result was that the Wiki contained the information needed to meet the goals of the topic (Enterprise Information Systems).

\section{E. Evaluation}

Analysis of the implementation of the information gathered with the different tools, assessment of the skills after carrying out the task of building the Wiki.

1) Group processes skills and behaviours of self-organization, integrity and openness

The scale aimed to evaluate the skills which were initially taken into consideration, but in the conclusion stage of the task in question. Thus, the skills which were initially identified in the students were expected to have improved and that those which had been less developed or were, in fact, lacking had now been mastered to some degree.

The nine items considered the following skills: Web and navigation skills 1); ability to accept and/or follow suggestions 2); time management and organization 3); clarity of communication and ease of expression of ideas 4); writing and editing skills 5); satisfying objectives 6); ability to work collaboratively (active listening, openness, flexibility, acceptance) 7); help, text editing 8); and group work/equal distribution of workload and responsibilities 9). The responses revealed an overall development in the skills mentioned above, in comparison with the evaluation carried out before the task in question.

The skills that were in evidence before the task was carried out showed an improvement of 3 to 4 degrees, and those which were hardly identified, or not at all, had developed by two or three degrees, meaning that all had increased.

In terms of analysis by group, groups one and five were the only ones who showed less internal agreement in the evaluation of some of the items, and it is curious to note that the same groups were the least positively assessed. This was in terms of web and navigation skills (these skills were poorer than the others), time management skills/meeting objectives (however this was justified by a lack of information on the part of the teacher responsible for the curricular unit in terms of schedule); and, finally, skills regarding offering and accepting help (which were evaluated as being less developed throughout the task by three of the groups, but which were observed as the task was being 
carried out, thus corroborating the improvement in these skills from the pre-task evaluation, where they had been identified as 'lacking'). Two groups also indicated a certain imbalance in the internal distribution of workload and responsibilities.

All the other skills which were considered were evaluated at the top of the scale, or near - which suggests that there was a perception of improvement/overall development of the skills by most of the students who took part in the activity.

The second data collection instrument focused mainly on aspects of satisfaction and benefits achieved through the task by means of the following questions:

- What parts of the activity were not completed in your group?

- What were the most important things that you learnt by carrying out this activity?

- What gave you the most satisfaction in this activity?

- What advice or suggestions would you give to groups who were going to carry out a similar activity to the one you did?

- What would you like to say to your the members of your group on these two lines?

Qualitative analysis of the answers reveals the following points:

- Question 1

Generally speaking, the groups considered that they had completed the task, met the objectives and Achieve the desired results; with the exception of one group which did not complete a PowerPoint presentation with the results of their task, and another which did not include the information they had gathered on the Wiki (justifying this with the fact that they would have been repeating what had already been put there by another group, which points to the need for groups to interconnect when they are working on the same themes)

- Question 2

Students indicated that the main points in terms of learning were related to:

1) Acquisition of knowledge: about information systems (variety, structure and functioning), about Wikis, and about how to use and apply new technologies in terms of organisation, and their respective benefits.

2) Acquisition of skills: collaboration skills, responsibilities, validation and selection of information, differentiating between main points and details, handling Wikis, putting information online, editing information that is copied and handling original text.

\section{- Question 3}

Students considered that the satisfaction of doing the task was mainly derived from the process, collaborating with other group members, and other groups, helping each other; in terms of results, they were satisfied when the Wiki came together as the final product of their group effort.

\section{- Question 4}

Regarding suggestions for the future, these focused on a greater connection between groups (when generating common information), asking for help in correcting mistakes and not being afraid of trying things out and getting them wrong, and interest in 'selling' their product or idea to businesses so that the task of building a Wiki did not die when the task was finished at the end of the semester (this enables students to have an idea of giving continuity to work carried out, and to see how this can be of real use at a business level, which is their area of study).

- Question 5

The answers to this question show almost completely (four students did not answer this question) that the students developed a strong sense of collaboration within each group as they carried out their task, recognizing the dedication and effort put in by all members of the group to achieve their aims, helping each other and creating a positive environment in their group.

The analysis of the data collected in these two instruments leads us to the conclusion that the results suggest a large degree of development in group processes skills and behaviours of self-organization, integrity and openness, which is more evident (or at least more easily perceived) than for web skills, along with development in writing and editing skills.

\section{2) Web skills}

After the Wiki was completed, there was only a slight improvement (from $77 \%$ to $96 \%$ ) in terms of personalising web navigation (safety settings, tool bars, home page, etc.), and from $95 \%$ to $5 \%$ in terms of students who had never created content on the internet, as this task of developing a Wiki was the only time that had done this .

\section{3) Involvement of managers}

Regarding the analysis of the responses to the questionnaire applied to the managers, in terms of their interest in Wikis for their professional practices, it was concluded that they see them as tools for bench marketing, resolving doubts and contributing to the training of Human Resources in certain areas of IS knowledge (even of a global nature). They stated that there should be a more practical component related to the characteristics of the industries and businesses in the region, different from the Wikis that already exist in IS, and they also called attention to the quality of the interface.

Overall, they showed interest in, and availability for, taking part in the development of the Wiki, with the exception of those cases where their professional activity does not involve taking part in IS planning in their organisation.

\section{CONCLUSION}

The paper presents the potential of Wiki tools and describes their pedagogical potential in learning processes in Higher Education (HE) contexts. The use of Web 2.0 tools can play an important role in developing students' professional skills in such contexts and we need to use these tools in order to innovate in pedagogical terms.

Taking into account the advantages of using Wikis in HE that are presented in the relevant literature, we were interested in validating the different types of outcomes resulting from WIKI construction: Objective Learning Outcomes (Direct), Metacognitive Outcomes (Indirect), Collaboration Outcomes (Indirect); these outcomes were explored in teaching and learning processes in classes of Information Systems Management in an HEI in Portugal. We 
also considered the interest that managers in the region's businesses might have in being involved with the Wiki construction process as, in the future, this would provide students with the opportunity to engage with professionals from, and in, the field, and this would teach these students the importance of collaborating with such professionals to enrich Wiki contents and goals.

From the results of the case study presented here, we can conclude that teaching and learning through Wikis contributes greatly to the development of group processes skills and behaviours of self-organization, integrity and openness, This is more evident (or more easily perceived) than the development of web skills, and this is why their application in teaching/learning contexts should be valued and disseminated in academic contexts, as well as being linked to related professional contexts.

\section{REFERENCES}

[1] European Commission (2008c), Commission Staff Working Document, The use of ICT to support innovation and lifelong learning for all - A report on progress, SEC (2008) 2629 final.

[2] R. Ferdig, "Examining social software in teacher education," Journal of Technology and Teacher Education, vol. 15, no. 1, pp. 5-10, 2007.

[3] D. H. Jonassen, J. Howland, R. M. Marra, and D. Crismond, Meaningful learning with technology, 3rd ed., Columbus, $\mathrm{OH}$ Merrill/Prentice Hall, 2007.

[4] A. Graham, Web 2.0 and the changing ways we are using computers for learning: What are the implications for pedagogy and curriculum? 2007.

[5] T. Rudd, F. Colligan, and R. Naik, "Learner Voice," Futurelab Handbook, 2006.

[6] T. Rudd, C. Gifford, J. Morrison, and K. Facer, "What if ... Re-Imagining Learning Spaces," Futurelab Opening Education Reports, 2006b.

[7] T. Rudd, D. Sutch, and K. Facer, "Towards new learning networks," Futurelab Opening Education Reports, 2006.
[8] G. Fischer and S. Masanori, "Supporting self-directed learners and learning communities with sociotechnical environments," Research and Practice in Technology Enhanced Learning, vol. 1, pp. 31-64, 2006.

[9] D. W. Johnson and F. P. Johnson, Joining together: Group theory and group skills, 9th ed., Boston, MA: Pearson Education, 2006.

[10] K. Parker and J. Chao, "Wiki as a teaching tool," Interdisciplinary Journal of Knowledge and Learning Objects, retrieved on December 7 , 2009.

[11] G. Siemens, Knowing Knowledge, 2006.

[12] C. Dede, "Planning for neomillennial learning styles," Educause Quarterly, vol. 28, no. 1, pp. 7-12, 2005.

[13] S. Mader, "Wikipatterns," Hoboken, NJ: Wiley, 2008.

[14] D. Tapscott and A. Williams, "Wikinomics: How mass collaboration changes everything?" New York: NY: Portfolio Hardcover (Penguin), 2006.

[15] W. Richardson, "Blogs, Wikis, podcasts and other powerful Web tools for classrooms," Thousand Oaks, CA: Corwin Press, 2006.

[16] R. Gomes and L. Sousa, "Contributions to a 2.0 strategy in higher education," Journal of Communication and Computers, vol. 8, no. 10, pp. 917-923, October 2011, David Publishing Company, ISS 1548-7709.

[17] K. Olesen and M. D. Myers, "Trying to improve communication and collaboration with information technology: An action research project which failed," Information Technology and People, vol. 12, no. 4, pp. 317-328, 1999.

[18] J. A. West and M. L. West, Using wikis for online collaboration, Jossey Bass: John Wiley, 2009

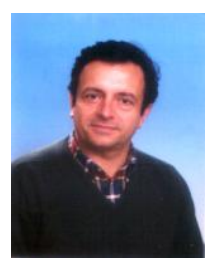

Rui Gomes was born on July 29, 1954 at Viana do Castelo, Portugal. He received his $\mathrm{PhD}$ in computer science by University of Coimbra, Portugal. He is a professor and coordinator of scientific area of Eletronics and Infornatics and of the Computer Engineering and Multimédia Group, teaching courses in the Bachelor of Computer Engineering and Master in Information Systems Technology and Management in the Polytechnic Institute of Viana do Castelo. He was member of CISUC Systems and Informatics Centre of the University of Coimbra from 1994 to 2011, engaged in enterprise architectures research activity and after 2011 is member of ISTOS (IST in Organizations and Society) Group, of the research unit of the School of Engineering - University of Minho - ALGORITMI 